\title{
Plantar bananeira: exercícios práticos e contextuais
}

\author{
Silfarlem Oliveira (UDESC)
}

\begin{abstract}
[PLANTAR BANANEIRA] Ficar de cabeça para baixo, com o corpo esticado verticalmente, apoiado nas mãos. No jogo de capoeira, espécie de movimento acrobático em que o capoeirista apoia as mãos no chão, dá um impulso e eleva o corpo verticalmente, permanecendo parado, de cabeça para baixo. Há quem diga, digo eu, que tal metáfora decorre das características de reprodução da planta em questão. A semente da banana é o próprio pé que dever ser plantado de cabeça para baixo.
\end{abstract}

[HACER EL PINO] Colocarse una persona en posición vertical invertida sujetándose con las manos en la superficie. Antiguamente se decía "hacer pinos", expresión que se usa también para expresar que un niño está dando sus primeros pasos. A eso le tenemos que sumar el hecho de que pino [árbol] es un adjetivo que significa "muy pendiente o muy derecho". Por tanto, se puede ver el origen de la expresión como que en gimnástica el ejercicio de "hacer el pino" consiste en ponerse muy derecho (solo que con los pies hacia arriba, que si no, no tiene gracia), o incluso que en esa posición uno mantiene la verticalidad a duras penas, tal y como hace un niño que está haciendo pinitos. De hecho, si a una persona en esa posición le dices que intente andar un poco con las manos, andará igual que un bebé que está aprendiendo a caminar.

[EXERCÍCIOS PRÁTICOS E CONTEXTUAIS] Prezada leitora e prezado leitor, os exercícios que aqui seguem reunidos são um convite a uma experimentação de ideias em torno da prática artística e didática em suas múltiplas facetas de agregação e desagregação. Conto com a participação de você para que este texto seja um texto (não) lido (embora, haja vista, considero a leitura uma prática con-textuada). Falando em "texto", deixo, igualmente, a critério das leitoras e dos leitores em que hemisfério situar o conjunto de letras apresentado: artigo/exercício/ensaio/proposição/jogo... Todas as formas de escrita - seja acadêmica, didática ou artística - gozam de uma reputação. Algumas escritas têm reputação de objetiva, algumas de explicativa e algumas outras de experimental. Ainda assim, cada qual a sua maneira deliberativa, guarda uma circunvizinhança que as une entre si, a linguagem. A linguagem como veículo. Dito isso, o caminho que gostaria de percorrer 
com você, neste artigo, diz respeito a uma tentativa de transtornar a linguagem como veículo a partir de exercícios práticos e contextuais. Uma espécie de conhecimento por desorientação, deslocamento e inserção. Assim, de cabeça para baixo, depois de plantar bananeira ou durante, considere forjar outras formas de dizer o não dizível. A linguagem também se faz pelo o que ela deixa de fora. Portanto, convido você a exercitar uma escrita (acadêmica, didática e artística) que seja uma construção de formas de vida, por assim dizer, menos veicular (explicativa) e mais descritiva/participativa. Como forma de conhecimento, a diferença que Luis Camnitzer faz entre duas modalidades de descrição dos acontecimentos artísticos são compatíveis com essa aspiração. Ele propõe no lugar do exercício de uma descrição explicativa o exercício de uma explicação contextual. Eu prefiro chamar de descrição autorreflexiva. Fugir dos esquemas que homogeneízam e mercantilizam as formas e as experiências, seja do artista, do público, do professor, do aluno, do pesquisador, do leitor requer um constante reposicionamento prático e discursivo. Enquanto elemento vinculante, os esquemas de anulação da experiência dos interlocutores são os mesmos que fazem a escola e o museu (como instituições) funcionar a partir de duas lógicas entranhadas em nossa existência ocidental/capitalista. A vida como fábrica (lógica consumista) e a vida como banco (lógica da propriedade). Como artistas e etc., em primeiro lugar calibramos nossa comunicação (ajustamos ela à audiência), em segundo lugar, ao mesmo tempo, nossa comunicação precisa ser capaz (ou pelo menos arriscar) de transtornar os padrões de visibilidade e inteligibilidade adquiridos (inclusive dentro do espaço acadêmico). Além disso, a ideia de formular exercícios práticos e contextuais está vinculada a uma abordagem propositiva que busca situar em perspectiva uma espécie de retorno ao atelier como estratégia 
de revitalização dos procedimentos pedagógicos do ensino da arte. Concomitantemente, a formulação de procedimentos artísticos pautados em construções discursivas e contextuais, entre informação e experiência como polos não repulsivos, coloca os espaços tradicionais do fazer "ensino" (aula) e do fazer "arte" (atelier) em reviravolta. Todos (artistas, professores, pesquisadores) observamos que as preocupações do fazer artístico assim como do fazer ensino, na era atual, sofreram deslocamentos de condução. Incorporaram outros fazeres, outros saberes e problemáticas que extrapolam o limite do estúdio e da sala de aula. Neste compasso contextual, pensar o lugar de apresentação ou de uso talvez seja de maior importância do que isolar o lugar de produção e reprodução do conhecimento. Faz 40 anos que Daniel Buren ao falar do trabalho in situ definiu o museu (e o atelier como extensão do museu) como o lugar no qual a arte se sustenta: "Todos estão preocupados com a própria significação do objeto que é produzido. Poucos prestam atenção ao lugar em que esse objeto é visível, como é visível, quem o torna visível...". Seguindo o caminho de Buren e da "crítica institucional, eles nos lembram de um fato que deveria interessar a todos produtores (artistas, professores, pesquisadores, historiadores, curadores e críticos) engajados em uma "repolitização" da arte. A localização e a acomodação, o enquadramento, seja no museu ou fora dele, das práticas artísticas como uma inserção autocrítica da e na cultura. Isso implica, citando outro artista, Joseph Kosuth, uma dupla tarefa de autorreflexão espiralada: "El arte, según han argumentado algunos, describe la realidad. Pero también se puede argumentar que a diferencia del lenguaje, las obras de arte simultáneamente describen cómo lo describen. Entonces, una obra de arte, como una doble máscara, [ofrece] la posibilidad no sólo de una reflexión sobre sí misma, sino de 
una doble reflexión indirecta sobre la naturaleza del lenguaje, a través del arte, sobre la cultura misma. 'No olvides - escribe Wittgenstein - que un poema, aunque esté compuesto en el lenguaje de la información, no se usa en el lenguaje-juego de dar información'." Para Kosuth a arte (a secas) é como um espelho que ao refletir uma realidade já dada descreve, ao mesmo tempo, seu mecanismo de construção. Com isso, sua estrutura operacional (da arte) em constante redefinição in situ, semanticamente deflagra elementos em funcionamento. Temos assim uma dialética autorreflexiva capaz de expor e isolar as contradições de nossas instituições normalizadoras. É quando nosso "marco discursivo", como forma de construção de mundo, se faz visível que podemos perceber que as práticas (culturais, políticas, artísticas...) são diferentes fases da mesma coisa. Em 2016 publiquei (na Revista Apotheke n.2 dedicada a Processos criativos) um artigo/carta que apontava para questões contextuais desprendidas da relação entre artista/escritor-espectador/leitor e professor-aluno. Hoje, passados dois anos, retomo algumas daquelas questões para, em 12 exercícios que entrelaçam práticas discursivas, práticas artísticas e práticas didáticas, oferecer aos leitores a possibilidade de articular suas próprias proposições e considerações de uma AULA ATELIER (de cabeça para baixo e espelhada). 
T9il(9ts s[uss

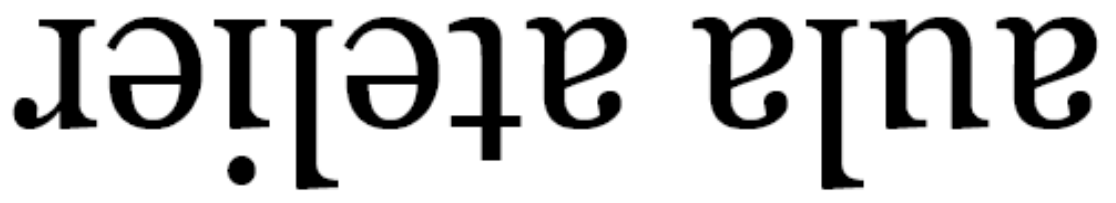




\section{EXERCÍCIO I}

[Ensaio para uma (in) ficção por contato] Encontre uma xerox que realiza serviços de cópias diversas, tanto de livros quanto de documentos. Recolha todas as folhas que foram descartadas pelos usuários e delas faça bolinhas para serem lançadas ao ar. Em 2015, na recém nomeada AULA ATELIER (invertida e espelhada), realizamos pela primeira vez a ação/proposição/instalação de desorientação. Depois de coletar aproximadamente 1000 folhas de papel pelas xerox da redondeza, amassamos cuidadosamente uma a uma. As folhas amassadas viraram bolinhas de papel, por fora todas iguais (papel em brancol por dentro fragmentos de informações. Frequentemente, numa xerox, é usado apenas um lado das folhas de papel para fazer cópias, o outro lado da folha permanece em branco. Assim sendo, amontoadas irregularmente sobre uma mesa, as bolinhas de papel, aparentemente idênticas, formavam um monte branco (Es lo mismo pero no es igual). Um "castelo" de informações, bolinhas prontas para serem lançadas ao ar, intercambiadas e eventualmente desamassadas e lidas. Uma colagem de informações espacializadas e sobrepostas ao acaso ou simplesmente uma (in) ficção por contato. 


REVISTA APOTHEKE
ISSN 2447-1267
V.4, n.3, ano 4, 2018

Um lance de bolinhas de papel

jamais

abolirá o acaso...

...mesmo

. . uma sala

...um contexto

...trocas de olhares

...combinações ditas e não ditas

...sem palavras e com palavras 


\section{EXERCÍCIO II}

[Jogo das (in)visibilidades ou como intercambiar miradas] Livremente adaptado a partir das obras "eu não sou vista' de Carolina Moraes e "Pequena Estória em duas linhas" de Leto Santos.

Escolha uma linha e siga!

( ) Tornar visível outras visibilidades, outros modos de ser...

( ) Ficar visível pela invisibilidade, pela não categorização..

( ) Ficar invisível e visível simultaneamente...

( ) Ficar visível procurando a invisibilidade como amiga...

( ) Identidade transitória...

( ) Ora visto, ora não visto...

( ) Dupla identidade...

( ) Incorporar outro...

( ) Sinalizar condições existentes...

( ) Despir-se de categorias...

( ) Repensando a atuação como...

( ) Deixar de atuar como...

( ) Assumindo uma postura mais flexível como...

( ) Trocando de "casaco"...

( ) Tornar-se ou incorporar... 


\title{
EXERCÍCIO III
}

[Alguém me contou que ora estamos isso, ora estamos aquilo. Ora estamos isso, aquilo e aquilo outrol Como desfazer duplos como oposição/negação e construir duplicidades pela multiplicidade?

\author{
artista $x$ professor \\ professor $x$ pesquisador \\ professor $x$ aluno \\ experiência $x$ informação \\ forma x conteúdo \\ prática x teoria \\ história x ficção \\ sujeito $x$ objeto \\ corpo x alma \\ razão x ilusão \\ real x imaginário \\ subjetividade $x$ objetividade \\ simplicidade x complexidade \\ diversidade $\mathrm{x}$ singularidade \\ conhecimento x ação \\ atividade $x$ passividade
}




\section{EXERCÍCIO IV}

Complete ou acrescente círculos em fluxus para um breve panorama contextual da arte e da vida, da vida da arte e da arte da vida.

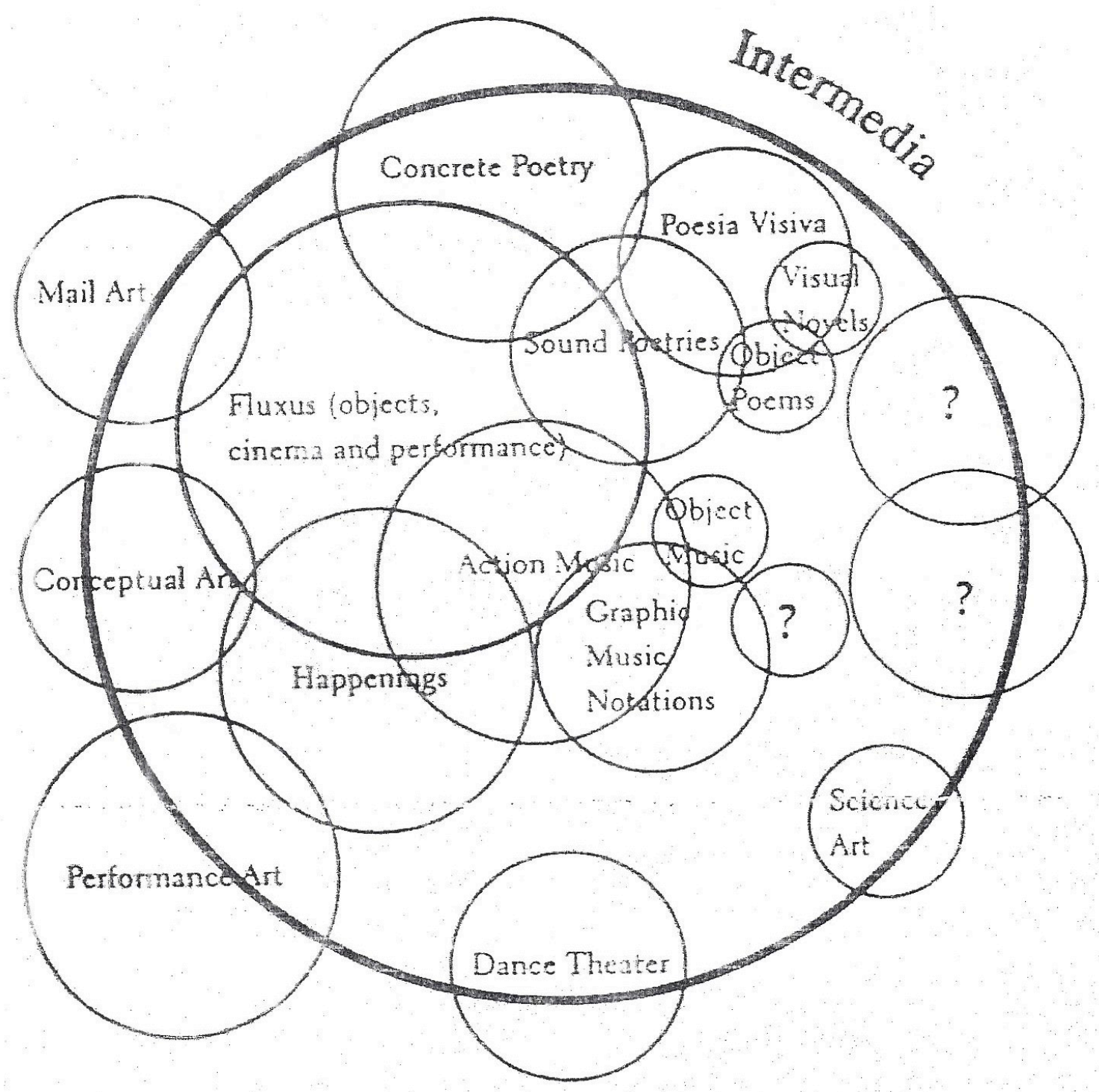




\section{EXERCÍCIO V}

[Questione mesmo]. Colecione perguntas. Assim descreve Yoko Ono em Peça de questão: "A peça significa um diálogo ou um monólogo de questões continuas, respondidas apenas por perguntas".

Como se deslocar do lugar onde se está sem abandoná-lo? Incompatibilidade entre tautologia e política? Como gerar um deslocamento pela aproximação? Em que medida proposições contextuais podem ser entendidas como procedimentos autorreflexivos? Até que ponto é útil fazermos uma distinção rígida entre políticas da arte (tautologia) e arte política? Temos que escolher entre uma arte autorreflexiva e uma arte política? Processos autorreflexivos são herméticos, descontextualizados e apolíticos? Qual a relevância do trânsito entre tautologia e política para produção artística contemporânea? Mundos dentro de mundos? "Um doido que estranha sua própria alma"? Por que não se pergunta? O que designam, pois, as palavras dessa linguagem? Como posso mostrar isso, a não ser na maneira do seu uso? Essa palavra é usada de fato desse modo na língua em que ela existe? Onde está o mesmo? Quando começa uma proposição? E quando termina? Como desfazer duplos (como oposição/negação) e construir duplicidades pela multiplicidade? A memória é um túnel de perguntas? Dizer pósestúdio não é o mesmo que dizer estúdio expandido? o problema da autoridade do discurso, ou da hierarquia dos saberes, é resolvido pela morte do autor, pela perda da identidade, ou pelo compartilhamento que busca mais do que uma igualdade acrítica, uma desclassificação? Se, como comenta Duchamp, "aqueles que olham são os que fazem os quadros", o 
leitor/ouvinte/espectador/aluno são consumidores de objetos e informações ou re-ruminadores (igualmente 'jogadores')? Como fazer zona de contato quando uma das partes é apagada? Como a arte como forma de conhecimento pode contribuir para a formação de um conhecimento acadêmico científico? Em que medida a pesquisa em arte é favorecida com a adoção de procedimentos acadêmicos científicos? Como cada um desses espaços (prática artística, prática científica, prática de ensino) trabalha com as noções de conhecimento prático e conhecimento teórico, há consenso sobre essas questões? Como incluir de forma efetiva na pesquisa em processos artísticos outros procedimentos investigativos e experimentais (previsibilidade infinita) que não dizem respeito apenas aos conteúdos dos documentos literários? Como equacionar processos criativos com processos de pesquisa (e ensino) de modo a conceder emancipação propositiva a ambas as formas de conhecimento?... 


\title{
EXERCÍCIO VI
}

[Dezesseis posições de contato e tensão, exercite!] Outras combinações de contato e tensão podem ser exercitadas, assim como outras palavras-chave acrescentadas "aluno" "espectador", "dentro" "fora", "participação" "repartição", "jogo" "proposição", "mercado" "circuito", "atelier" "apresentação", "conhecimento" "experiência", ...).

\author{
artista-professor (a) \\ professor (a)-artista \\ professor (a)/artista \\ artista/professor (a) \\ PROFESSOR (a) rtista \\ ARTISTAprofessor (a) \\ PROFESSOR (A) RTISTA \\ professor (a)rtista \\ artista...professor (a) \\ professor(a) ...artista \\ atsitr (a) rosseforp \\ professor (a) rtista \\ professor (a) rtistaetc \\ a/r/tography \\ professor(a) e artista \\ artista e professor(a)
}




\section{EXERCÍCIO VII}

[Resenha vocalizada e anotada] Escolha um livro nas medidas desejadas. Convide um (a) parceiro (a) e em dupla atuem. Um lê, página por página, a primeira letra de cada frase do livro escolhido e o outro registra as letras sobre uma folha em branco. Outros procedimentos de leitura e registro podem ser adotados. Uma vez concluídas as anotações (o alojamento gráfico dos corpos vocalizados), procurem na sequência de letras, palavras; elas formarão a resenha do livro escolhido. Nessa fase, é desejável que os resenhantes/leitores possuam treinamento com caça-palavras. Esgotada a caçada, a resenha estará pronta. Junte todas as palavras encontradas e as publique. Com elas, nem mais nem menos, o procurador oferece ao leitor um panorama detalhado do conjunto. Sempre bom lembrar as palavras de Borges, todos os livros contém os mesmos elementos (as letras do alfabeto) colocados em ordens desiguais: "Quando menino, eu costumava me maravilhar com o fato de as letras de um volume fechado não se misturarem nem se perderem no decorrer da noite". 


\section{LA EDUCACIÓN DEL DES-ARTISTA}

E C D D P P C E D D L M L T O O E E S E U N S R O D E L C P T M S H M C C E N C T D P D A V C L C E D S A K T L D P L E Q P C Q E Y Q Q T D S S Q L D M T Q A C M T Q P P G Q P

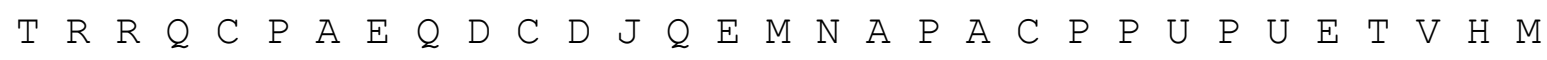

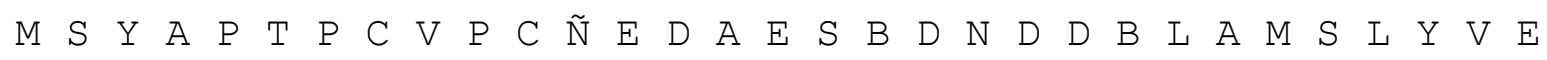
S E B B T H Y K P S B R S L P A D U E G C A S E J D U D S M C

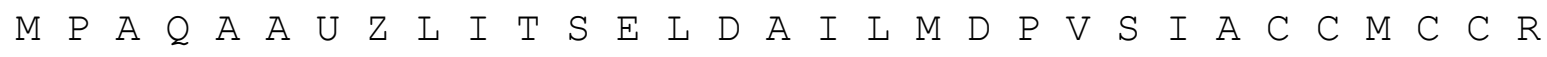
$\begin{array}{llllllllllllllllllllllllllll}C & C & G & C & U & S & C & U & S & E & Y & C & D & D & C & A & A & E & T & C & D & T & M & E & F & R & L & P\end{array}$ C C C C T D C C E L E L A M D M D P V D S A Y P S L L P S R N A A G T M G L E C E A L C O P D S S D E L O D L D $L N$ T P R N S T C S R P E D E Q N C D T C R Q B C P T F I P E C D E D S S P P T U D T T S N D S R Y D P V S T E H R T E L P P M E L P C E R E E D E H V G B S O A Q S P E S M D A L D E T

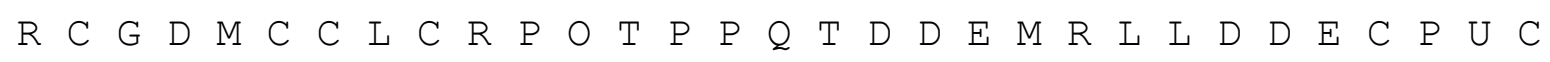

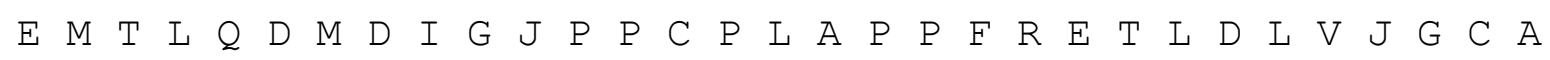
Q U E G D Q L E A S M T N E L J M P C O C D D R P C U P Q D E E U S D Y M S A F U D N T S F D B D T M E U F A E C D $S$ D

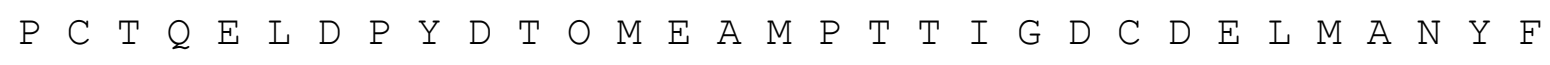
O D I A A Q S E D W C A O S A T D M Q J Z I J U U M T U D M D

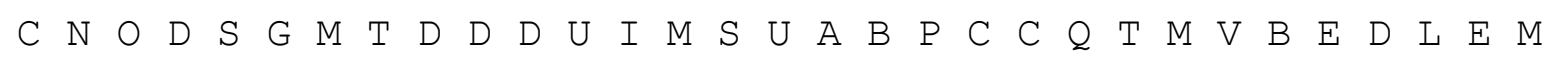

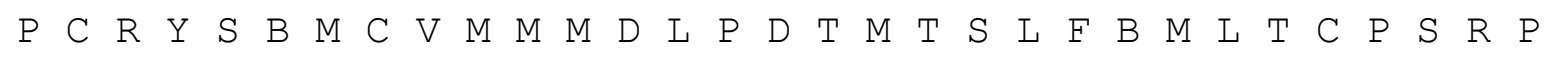
$N E D C R$ E

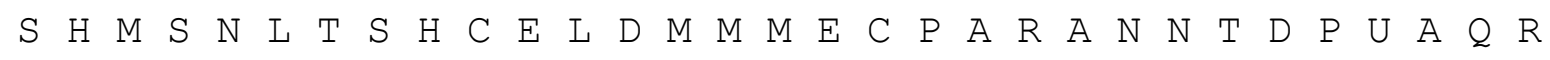
I D T C P C T C E B L C A D E G C C P S A P L D D P L Q A E E $P$ D Y C E Q D E T I A V N U L D C L L I A $Q$

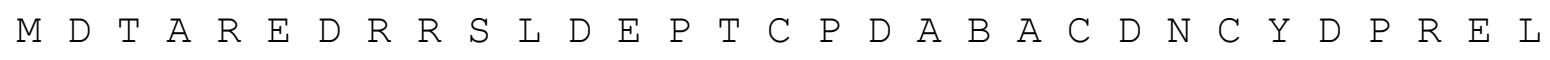

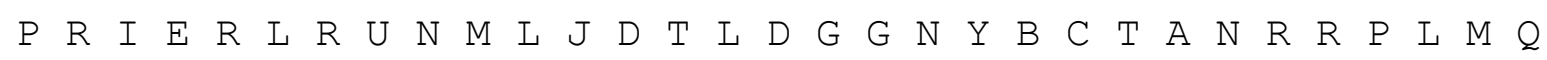

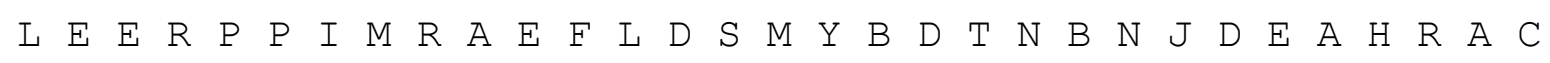
C T C C P E U D L L C D L N C S C C A A $N$ R I J A M M D D P E D A V M S Y C Q L $P$ E 


\section{EXERCÍCIO VIII}

[CULEBRÓN uma novela de língua solta]. Baseada em realidades ajudadas e modificadas. A partir do jogo do bicho + pedra monte diálogos combinando personagens, use sua linguagem (verbal e não verbal) e suas formas de vida. Para esse exercício de tradução dos modos de ser (tudo fala: seres animados e des-animados) facilitamos cinco indicações, cinco argumentos para um roteiro.

SCRIPT

- Avestruz

- Gato

- Águia

- Jacaré

- Burro

- Leão

- Borboleta

- Macaco

- Cachorro

- Porco

- Cabra

- Pavão

- Carneiro

- Peru

- Camelo

- Touro

- Cobra

- Tigre

- Coelho

- Urso

- Cavalo

- Veado

- Elefante

- Vaca

- Galo

- pedra 
(ARGUMENTO GUIMARÃES ROSA) "Mecê tá ouvindo, nhem? Tá aperceiando... Eu sou onça, não falei? Axi. Não falei - eu viro onça? Onça grande, tubixaba. Ói unha minha: mecê olha unhão preto, unha dura... Cê vem, me cheira: tenho catinga de onça? Preto Tiodoro falou eu tenho, ei, ei... Todo dia eu lavo corpo no poço... Mas mecê pode dormir, hum, hum, vai ficar esperando camarada não. Mecê tá doente, carece de deitar no jirau. Onça vem cá não, cê pode guardar revólver ... Onça vem, Maria-Maria, come mecê... Onça meu parente... Ei, por causa do preto? Matei preto não, tava contando bobagem... Ói a onça! Ui, ui, mecê é bom, faz isso comigo não, me mata não... Eu Cacuncozo... Faz isso não, faz não... Nhenhenhém... Heeé!... Hé... Aar-rrâ... Aaâh... Cê me arrhoôu... Remuaci... Rêiucàanacê... Araaã...Uhm..."

(Argumento João Cabral de Melo Neto) "Uma educação pela pedra: por lições; Para aprender da pedra, frequentá-la; Captar sua voz inenfática, impessoal (pela dicção ela começa as aulas). A lição de moral, sua resistência fria. Ao que flui e a fluir, a ser maleada; A de poética, sua carnadura concreta; A de economia, seu adensar-se compacta: Lições da pedra (de fora para dentro, Cartilha muda), para quem soletrá-la. Outra educação pela pedra: no sertão (de dentro pra fora, e prédidática). No Sertão a pedra não sabe lecionar, E se lecionasse, não ensinaria nada: Lá não se aprende a pedra: lá a pedra, Uma pedra de nascença, estranha a alma".

(ARGUMENTO WITTGENSTEIN) "Uma criança recém-nascida não tem dentes." - "Um ganso não tem dentes." - "Uma rosa não tem dentes." - Esta última - dir-se-ia - é evidentemente verdadeira! Mais certa até que a do ganso. - Mas não tão claro. Pois onde uma rosa deveria ter dentes? O ganso não tem nenhum nos seus maxilares. E naturalmente, não tem também nas 
asas, mas ninguém tem isto em mente quando diz que ele não tem dentes. - É como se alguém dissesse: a vaca mastiga sua ração e, com seu estrume, aduba a rosa; portanto a rosa tem dentes na boca de um animal. Isto não seria absurdo, porque desde o início não se sabe onde se teria de procurar, na rosa, os dentes. (Relação com 'DORES NO CORPO DO OUTRO'). POsso saber o que o outro pensa e não o que eu penso ...' o interior está oculto para nós.' [...] Dizemos também de uma pessoa, que ela é transparente para nós. Mas é importante para esta consideração que uma pessoa possa ser um completo enigma para outra. Isto se experimenta quando se chega num país estrangeiro, com tradições totalmente desconhecidas pra nós e aliás, mesmo que dominemos a língua desse país. Não se compreende as pessoas. (E não porque não se sabe o que elas falam para si mesmas.) Não podemos nos encontrar nelas. ... Se um leão pudesse falar, não poderíamos compreendê-lo."

(Argumento Jacques Rancière) "Por desentendimento entendemos um tipo determinado de situação de palavra: aquela em que um dos interlocutores ao mesmo tempo entende e não entende o que diz o outro. O desentendimento não é o conflito entre aquele que diz branco e aquele que diz preto. É o conflito entre aquele que diz branco e aquele que diz branco mas não entende a mesma coisa, ou não entende de modo nenhum que o outro diz a mesma coisa com o nome de brancura. [...] Os casos de desentendimento são aqueles em que a disputa sobre o que quer dizer falar constitui a própria racionalidade da situação de palavra. Os interlocutores então entendem e não entendem aí a mesma coisa nas mesmas palavras. [...] Compreender não é mais do que traduzir. [...] Aprender e compreender são duas maneiras de exprimir o mesmo ato de tradução. Nada há aquém dos textos, a não ser a vontade de se expressar, isto é de traduzir. Esse trabalho poético de tradução está no cerne de 
toda aprendizagem [...] aprender não para ocupar a posição do intelectual, mas para praticar melhor a arte de traduzir, de pôr suas experiências em palavras e suas palavras à prova, de traduzir suas aventuras intelectuais para uso dos outros e de contratraduzir as traduções que eles lhe apresentam de suas próprias aventuras. [...] A emancipação, por sua vez, começa quando se questiona a oposição entre olhar e agir [entre falar e escutar], quando se compreende que as evidências que assim estruturam as relações do dizer, do ver e do fazer pertencem à estrutura da dominação e da sujeição. O espectador também age, tal como o aluno ou o intelectual [...] são ao mesmo tempo espectadores distantes e intérpretes ativos do espetáculo que lhes é proposto. [...] Não há forma privilegiada como não há ponto de partida privilegiado. Há sempre pontos de partida, cruzamentos e nós que nos permitem aprender algo novo caso recusemos, em primeiro lugar, a distância radical; em segundo, a distribuição dos papéis; em terceiro, as fronteiras entre os territórios."

(Argumento Paul Valéry) "Os dois pensamentos tinham certamente semelhança, pois cada um se atormentava com o distanciamento de seu comparsa. [...]dos dois lados do abismo falava-se a mesma coisa e dois corações ignorantes um do outo batiam quase igual. [...]. Havia como que um abismo entre dois pensamentos que eram quase o mesmo; e dos dois lados do abismo uma mesma dor, ou quase a mesma. Pois duas almas divididas se moviam separadamente em direção à sua semelhança; pois cada uma se atormentava por causa do afastamento interior de sua outra mesma[...]e a tornava ora muito horrível e ora muito amável. E ora muito odiada, e ora muito amada [...]." 
REVISTA APOTHEKE

ISSN 2447-1267

v.4, n.3, ano 4, 2018

\section{EXERCÍCIO IX}

[Quem são os novos doces bárbaros?] Os sem papel, os sem propriedades, os desocupados, os sem gênero, os vermelhos, os amarelos, os sem classe, as bárbaras...

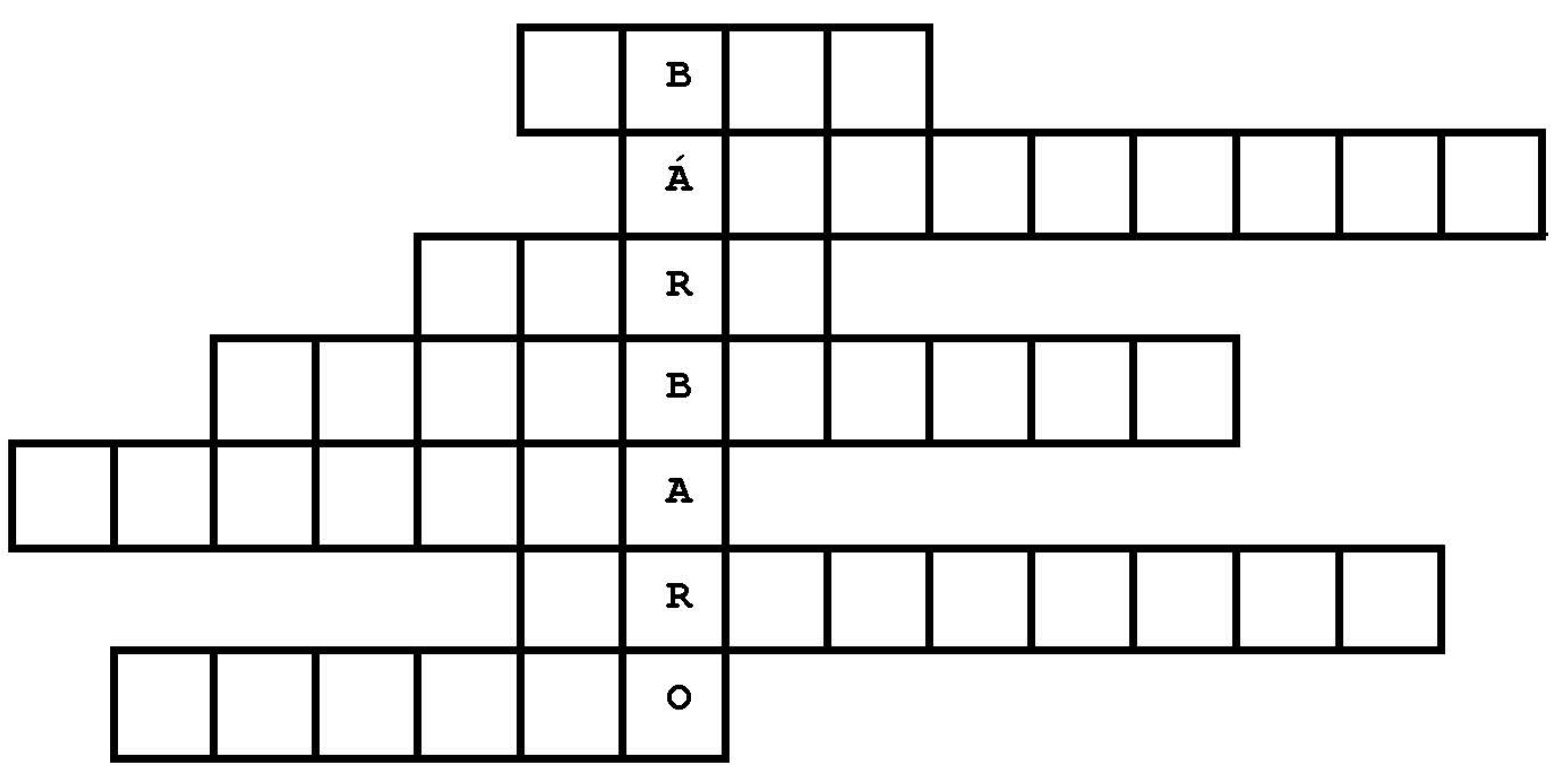

1. Tem poder sobrenatural conforme crença popular

2. Estado e condição de um povo que goza de independência

3. Qualquer pessoa ou coisa diversa daquela que fala

4. Espaço em um escrito que se deixa sem preencher

5. Ofício das antigas companhias cômicas

6. Transmissão oral de acontecimentos

7. O mesmo 


\section{EXERCÍCIO X}

[Três anúncios para uma Ação] Baseado livremente nas frases/cartazes de Luis Camnitzer: "EL MUSEO ES UMA ESCOLA EL ARTISTA APRENDE A COMUNICARSE; EL PÚBLICO APRENDE HACER CONEXIONES" e "LA ESCUELA ES UNA FÁBRICA". Escola, fábrica, museu e [banco] o que estas instituições tem em comum? Realize uma ação prática e discursiva nos espaços institucionais da escola, da fábrica, do museu e do banco. Realize uma ação (no espaço público) longe dos tentáculos práticos e discursivos da vida como escola, como fábrica, como museu e como banco. 
ISSN 2447-1267

v.4, n.3, ano 4, 2018

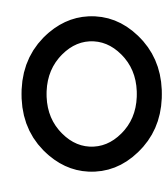

\section{Museu}
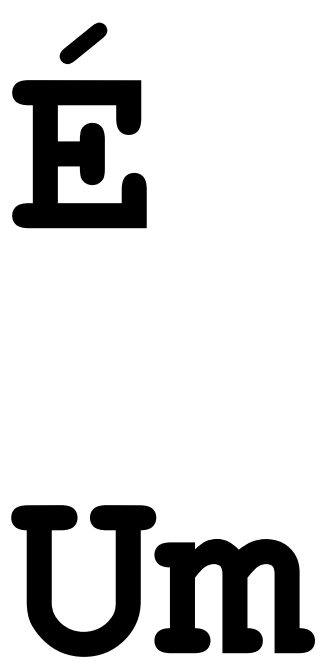

Banco 


\section{EXERCÍCIO XI}

\section{[Elogio aos secundaristas] Uma e três canções para uma escola com partido (com posição): cantar em vozes sobrepostas.}

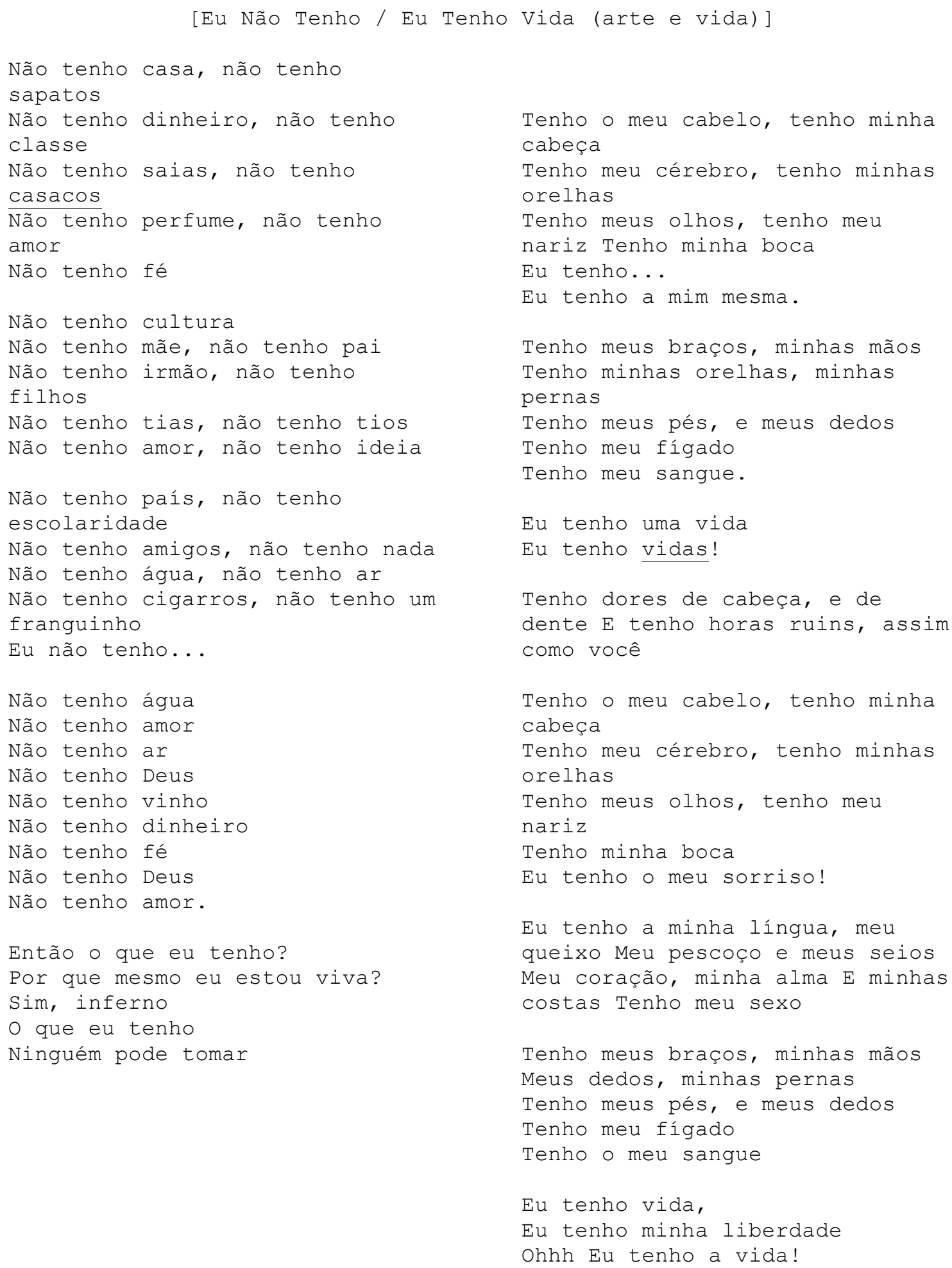

Tenho o meu cabelo, tenho minha cabeça

Tenho meu cérebro, tenho minhas orelhas

Tenho meus olhos, tenho meu

nariz Tenho minha boca

$\mathrm{Eu}$ tenho...

Eu tenho a mim mesma.

Tenho meus braços, minhas mãos Tenho minhas orelhas, minhas pernas

Tenho meus pés, e meus dedos

Tenho meu fígado

Tenho meu sangue.

Eu tenho uma vida

Eu tenho vidas!

Tenho dores de cabeça, e de dente $E$ tenho horas ruins, assim como você

Tenho o meu cabelo, tenho minha cabeça

Tenho meu cérebro, tenho minhas orelhas

Tenho meus olhos, tenho meu nariz

Tenho minha boca

Eu tenho o meu sorriso!

Eu tenho a minha língua, meu queixo Meu pescoço e meus seios Meu coração, minha alma E minhas costas Tenho meu sexo

Tenho meus braços, minhas mãos Meus dedos, minhas pernas

Tenho meus pés, e meus dedos

Tenho meu fígado

Tenho o meu sangue

Eu tenho vida,

Eu tenho minha liberdade

Ohhh Eu tenho a vida! 


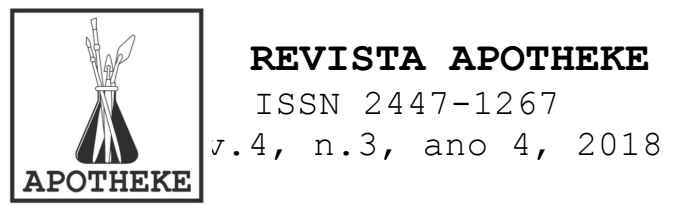

\author{
Nina Simone - Ain't Got No / I \\ Got Life \\ [Alguns chamam de técnica outros de estratégia (Deambulando)]
}

Una pierna que respiran

Veneno de serpiente

Por el camino del viento

Voy soplando agua ardiente

"El día a día había comenzado

entusiasmado y alegre"

- Dice (jajaja) Pasaporte

- Para donde vas caminando en esta noche tan fea

- ud no se anima

- Mire como esta el camino,

Anegadito

- El camino es lo de menos

- Lo importante es llegar

Tengo tu antídoto...

Pal' que no tiene identidad

Somos idénticos...

Pal' que llegó sin avisar

Vengo tranquilito...

Para los que ya no están, para los que están y los que vienen (x2)

Un nómada sin rumbo

La energía negativa yo la derrumbo Con mis pezuñas de cordero

Me propuse recorrer el continente entero

Sin brújula, sin tiempo, sin

agenda

Inspirao por las leyendas

Con historias empaquetadas en

lata,

Con los cuentos que la luna relata

Aprendí a caminar sin mapa...

A irme de caminata sin

comodidades, sin lujo

Protegido por los santos y los

brujos

Aprendí a escribir carbonerías en mi libreta

Y con un mismo idioma sacudir todo el planeta

Aprendí que mi pueblo todavía reza Porque las "fucking" autoridades y la puta realeza

Todavía se mueven por debajo de la mesa

Aprendí a tragarme la depresión

con cerveza
Mis patronos yo lo escupo desde las montañas

Y con mi propia saliva enveneno su champaña. Enveneno su champaña...

[ROLDAN:] Sigo tomando ron...

Tengo tu antídoto...

Pal' que no tiene identidad

Somos idénticos...

Pal' que llegó sin avisar

Vengo tranquilito...

Para los que ya no están, para los que están y los que vienen (x2)

En tu sonrisa yo veo una

guerrilla,

Una aventura un movimiento

Tu lenguaje, tu acento,

Yo quiero descubrir lo que ya

estaba descubierto

Ser un emigrante ese es mi deporte

Hoy me voy pal' norte sin

pasaporte, sin transporte

A pie, con las patas

Pero no importa este hombre se

hidrata

Con lo que retratan mis pupilas

Cargo con un par de paisajes en mi mochila,

Cargo con vitamina de clorofila,

Cargo con un rosario que me vigila

Sueño con cruzar el meridiano,

Resbalando por las cuerdas del

cuatro de Aureliano

Y llegarle tempranito temprano a

la orilla

Por el desierto con los pies a la

parrilla

Vamo' por debajo de la tierra como las ardillas,

Yo vo'a cruzar la muralla

Yo soy un intruso con identidad de recluso

Y por eso me convierto en buzo

Y buceo por debajo de la tierra

Pa' que no me vean los guardias

Y los perros no me huelan...

Abuela no se preocupe

Que en mi cuello cuelga la virgen

de la Guadalupe

[ROLDAN : ] 
Oye para todos los emigrantes del mundo entero... alla va eso...

[ A meta é dobrar a meta

(Resposta SEM FIM)]

O suficiente enquanto eu estiver vivo

ok, ok, ok, ok, ok, ok

Já sei que querem a minha opinião

Um papo reto sobre o que eu pensei

como interpreto a tal, a vil

situação

Penúria, fúria, clamor, desencanto Substantivos duros de roer

Enquanto os ratos roem o poder

Os corações da multidão aos

prantos

Alguns sugerem que eu saia no grito

Outros que eu me quede quieto e mudo

E eis que alguém me pede encarne o mito

Seja nosso herói, resolva tudo

ok, ok, ok, ok, ok, ok

Já sei que querem a minha opinião

Um papo reto sobre o que eu pensei

Como interpreto a tal, a vil

situação

Dos tantos que me preferem calado Poucos deles falam em meu favor A maior parte adere ao coro irado Dos que me ferem com ódio e terror ok, ok, ok, ok, ok, ok

Ainda querem a minha opinião

Um papo reto sobre o que eu pensei

Como interpreto a tal, a vil

situação

Que o nobre, nobre mesmo, amava os seus

Prezava mais o zelo e a compaixão

Tratava seu vassalo com afeição

A mesma que pelo cão e o cavalo

Então não falo, músico e poeta Me calo sobre as certezas e os fins

Meu papo reto sai sobre patins

A deslizar sobre os alvos e as metas

ok, ok, ok, ok, ok, ok

Sei que não dei nenhuma opinião

É que eu pensei, pensei, pensei, pensei

Palavras dizem sim, os fatos dizem não

Gilberto Gil - OK OK OK
Já para os que me querem mais ativo

Mais solidário com o sofrer do pobre

Espero que minha alma seja nobre 


\section{EXERCÍCIO XII}

[Breve coletânea de escritos de artistas] Para concluir os exercícios práticos e contextuais AULA ATELIER (invertida e espelhada) monte uma coleção de escritos como prática pedagógica. Coletar, colecionar/reunir e combinar, sejam objetos, imagens ou textos, são alguns dos procedimentos explorados por práticas artísticas contextuais de montagem. Sugerimos iniciar, o exercício, por uma lista de textos, como uma espécie de sumário ou de referências de consulta. Escolha os textos. Junte os textos numa ordem (preestabelecida ou por aproximação). (No nosso exemplo a distribuição dos textos foi por sorteio). Uma vez lidos escreva uma apresentação. Na arte, em algumas circunstâncias, os meios de enunciação (escritos e falados), textos, declarações, entrevistas, conversas e etc. são adotados, simultaneamente, como prática artística e como comentário sobre a própria atividade levada a cabo pelo artista (ou sobre a arte em geral), o que inclui também a atividade docente. Tais práticas artísticas compartilham, de modo geral, a visão de que o "ato de definição" não está separado do "ato de apreciação". Essa dupla (ex)posição como ato de visibilidade e ato de enunciação é o que torna a atividade artística uma forma pedagógica por si. Tal combinação quando praticada, ao meu ver, desfaz os papeis instituídos, abrindo caminho às metamorfoses do ser e do saber, e desta forma, conspira contra a padronização das práticas da vida. Como afirma Ricardo Basbaum: "Quando um artista é artista em tempo integral, nós o chamaremos de 'artista-artista'; quando o artista questiona a natureza e a função de seu papel como artista, escreveremos 'artista-etc' 


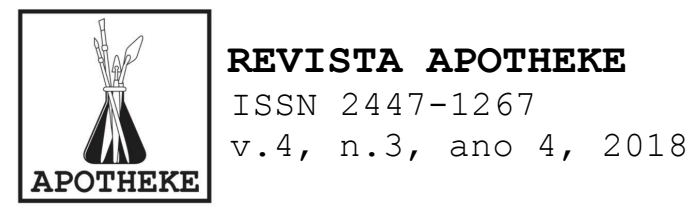

(de modo que poderemos imaginar diversas categorias: artistacurador, artistaescritor, artista-ativista, artista-produtor, artista-agenciador, artista-teórico, artista-terapeuta, artista-professor, artista-químico, etc)".

Declaración docente por Tania Bruguera; 0 artista como pesquisador por Ricardo Basbaum; Reflexões sobre 'pesquisas' de doutorado em Artes Visuais por Victor Burgin; Responda as seguintes questões Verdadeiras ou Falsas e Peça de questão por Yoko Ono; Arte y Pedagogía por Luis Camnitzer; The Education of the An-Artist, Part (III), (Fragmento: Learning Models) por Allan Kaprow; ¿Ha de ir el artista a la universidad? por Marcel Duchamp; A collection of mind-openers (in) Robert Filliou; A short note: Art, education and linguistic change por Joseph Kosuth; Conversando com Cage 'Pedagogia' por John Cage e Richard Kostelanetz; Diário: Seminário de Música de Emma Lake por John Cage; Teaching to learn (a conversation about 'How' and 'Why') por Joseph Kosuth; La ideia de Universidad por Ian Wallace; 0 desentendimento/O espectador emancipado/ 0 mestre ignorante por Jacques Rancière; La enseñanza del arte como fraude por Luis Camnitzer; Dominós: uma exposição do museu(trabalho in situ) por Daniel Buren; Carta aberta aos secundaristas por Peter Pál Pelbart; Manual da ciência popular por Waltercio Caldas; Da crítica às instituições a uma instituição da crítica por Andrea Fraser; Biblioteca de Babel por Jorge Luis Borges; Investigações Filosóficas por Ludwig Wittgenstein; Meu tio o Iauretê por Guimaraes Rosa; Alfabeto por Paul Valéry; Escritos (1966-2016), por Joseph Kosuth; Anteproyecto de proyecto de un pretendido panorama abarcativo/Arte de y para investigación por Edgardo-Antonio Vigo. 